\title{
ABC da Greve, de Leon Hirszman: a escrita da história em confronto
}

\section{Reinaldo Cardenuto}

\section{Resumo:}

A partir da análise de depoimentos concedidos por Leon Hirszman entre 1979 e 1981, o artigo investiga a genealogia do documentário $A B C$ da greve, em especial a proposta que o cineasta tinha em fazer de seu filme uma síntese dialética da greve metalúrgica de 1979 que servisse para instigar os operários a pensarem a sua própria praxis política. Partindo da expectativa de Hirszman em engajar-se, a partir deste processo de criação, nos debates sobre a abertura democrática, o texto também analisa a aproximação por ele estabelecida entre a prática do marxismo e o fazer documental, além de abordar as suas reflexões, naquele contexto histórico, sobre o cinema político no Brasil.

\section{Palavras Chave:}

Documentário brasileiro, $\mathrm{ABC}$ da greve, Leon Hirszman, greves metalúrgicas no ABC, ditadura militar.

\section{Abstract:}

From the analysis of depositions given by Leon Hirszman between 1979 and 1981, this paper investigates the genealogy of the documentary $A B C$ da greve, especially the filmmaker proposal of transforming his film in a dialectical synthesis of the metallurgical strike in 1979 which could serve for inciting the workers to think their own political praxis. Based on the Hirszman's expectation in engaging himself, from this creative process, in the debates on the democratic opening, the text also analyzes the approach he established between the practice of Marxism and the documentary filmmaking, moreover, it discusses his reflections, in that historical context, on political cinema in Brazil.

\section{Keywords:}

Brazilian documentary, $\mathrm{ABC}$ da greve, Leon Hirszman, metallurgical strikes in $\mathrm{ABC}$, military dictatorship.

"Meu risco sempre foi esse. Joguei no campo das minhas convicções. Eu jogo no campo da liberdade, pela liberdade. Eu não jogo no campo da hesitação e da noite. Não, não jogo nesse campo, porque eu acho que o intelectual que jogue no dia e que jogue em contato e que jogue na interação com o povo, numa perspectiva comum que seja de um processo de justiça social, de paz mundial e de democracia efetiva, de ampliação constante da democracia no país, eu acho que esse intelectual tem um caminho real" (entrevista concedida por Leon Hirszman à rádio Jornal do Brasil, setembro de 1981). 
Por questões jurídicas envolvendo o fechamento de sua produtora, a Saga Filmes, Leon Hirszman ficaria alguns anos, na década de 1970, sem envolver-se na direção de um longa-metragem cinematográfico. Após a realização de $S$. Bernardo (1972), adaptação da obra homônima de Graciliano Ramos, o cineasta conseguiria recursos para um novo projeto apenas em 1979, quando com apoio financeiro da Embrafilme resolveu levar às telas a peça de Gianfrancesco Guarnieri, Eles não usam black-tie, originalmente encenada pelo Teatro de Arena em 1958. Trabalhando em parceria com o dramaturgo, Hirszman se reunia com ele em São Paulo com a finalidade de roteirizar a obra teatral, atualizá-la para um novo contexto histórico, pós-golpe militar, no qual a esquerda comunista enfrentava o colapso de seu projeto político e a classe trabalhadora, predominantemente urbana e industrial, estava coibida de realizar livremente greves graças à lei 4330, sancionada em junho de 1964. No entanto, foi justamente quando os dois iniciavam o processo de adaptação de Eles não usam black-tie, que, no dia 13 de março de 1979, às vésperas da posse do general Figueiredo à presidência da República, eclodiu uma greve geral na região do ABC. Contrariando a repressão governamental e contando com a liderança central do sindicato de São Bernardo, o setor metalúrgico paulista paralisou as suas atividades para reivindicar, principalmente, reajustes salariais, melhorias nas condições de trabalho e estabilidade de emprego para aqueles operários que atuavam como dirigentes sindicais.

Diante deste quadro, que recolocava o movimento operário no centro das discussões, Leon Hirszman decidiu interromper por algum tempo a redação de seu roteiro para acompanhar de perto, com uma pequena equipe de filmagem, o desenrolar dos acontecimentos na greve metalúrgica. Em essência, tal disposição era mobilizada por dois fatores. Comprometido com o marxismo nas artes, compartilhando do pressuposto de que a representação da realidade social deveria vir acompanhada de um estudo rigoroso do contexto histórico, o cineasta deslocou-se para a região do ABC com a expectativa de conhecer, em pormenores, a situação da classe popular no final dos anos 1970. Levando-se em conta a necessidade de atualizar Eles não usam black-tie, seria uma oportunidade fundamental para estar ao lado dos trabalhadores, pesquisar seu cotidiano e suas contradições, evitando assim ficcionalizá-lo anacronicamente ou a partir de esquematismos típicos de uma dramaturgia política, de heroicização do povo, à qual Hirszman esteve ligado quando realizou o curta Pedreira de São Diogo, em 1962. Em oposição ao próprio idealismo de juventude, o cineasta desejava uma representação mais complexa do popular, mais humanizada, distante da leitura ortodoxa que impunha ao outro a caricatura do sujeito histórico à frente de uma teleologia revolucionária de fundo marxista. Como ele mesmo explica, em entrevista concedida para a rádio Jornal do Brasil, possivelmente em setembro de 1981 (1): "[O documentário] $\mathrm{ABC}$ da greve era um trabalho não só de documentação exterior, de estar perto do piquete, da repressão (...), mas também de entrar na casa do trabalhador, ver quem era o segurança daquela fábrica, porque se interessava pelo sindicato (...) Uma série de coisas que me enriqueceram muito, sabe? Chegando perto de uma realidade nova, de estar aberto a ela (...)" (HIRSZMAN, 1981).

Para além deste fator pontual, de $A B C$ da greve como ensaio para a adaptação de Eles não usam black-tie, também mobilizou Hirszman a possibilidade de integrar-se, pela primeira vez em sua vida, às mobilizações de uma greve geral. Embora ele tivesse se tornado, na geração do Cinema Novo, uma das principais vozes em compromisso com a luta popular, a sua experiência ao lado dos operários era quase nula e se restringia a uma breve passagem pela empresa Standard Electric, única oportunidade em que exerceu a sua formação universitária como engenheiro (2). O cineasta, como muitos dos envolvidos com o Partido Comunista Brasileiro, compartilhava da análise de que faltava aos artistas engajados uma aproximação com a praxis, ainda mais depois do golpe militar, quando o governo atuara no sentido de desarticular a aproximação histórica, intensa na primeira metade dos anos 1960, entre lideranças políticas do povo e da esquerda intelectualizada. Este desalinhamento, que intensificava para Hirszman a alienação do artista em relação à classe popular, poderia começar a ser revertido a partir do envolvimento com a greve, naquele momento saudada por ele como a emergência do operariado no cenário político nacional3, com a expectativa de uma possível articulação da "frente única" esquerdista contra o regime ditatorial. 
Deslocar-se em direção ao ABC significava, a partir do encontro com o operário, assumir de frente a luta política. E o documentário $A B C$ da greve seria uma peça fundamental no processo.

Na trajetória de Hirszman, exceção a alguns de seus filmes, como Imagens do inconsciente (1986), um aspecto essencial do documentarismo esteve relacionado com a urgência, por ele sempre sentida, em articular uma leitura em compromisso com o tempo presente, com questões fundamentais para pensar o Brasil no decorrer das décadas de 1960 a 1980. Influenciado pelo pensamento de Antonio Gramsci, em especial o conceito de "intelectual orgânico", seu fazer cinematográfico pressupunha assumir uma posição materialista diante da realidade, por vezes exercitando no documentário uma síntese dialética do presente, uma revelação crítica de conflitos sociais e culturais que poderia influenciar os debates contemporâneos e, quem sabe, agir no sentido de provocar uma praxis política.

Embora os filmes documentais de Hirszman tenham sido pouco vistos na época de suas feituras, o que implicou um inevitável afastamento das perspectivas de engajamento do cineasta, a concepção aqui brevemente apresentada esteve na origem de diversos de seus projetos. Em Maioria absoluta (1964), no qual a voz politizada dos analfabetos se contrapõe ao preconceito da classe média urbanizada, para quem aqueles seriam intelectualmente incapazes de participar do processo eleitoral democrático; em Ecologia (1973), filme educativo sobre as conseqüências perversas do consumo excessivo para o meio-ambiente; ou Partido alto (1976-82), no qual o samba de improvisação, simbolizado como autêntica representação do popular, é celebrado em resistência às padronizações impostas pela espetacularização da indústria cultural (4). Até mesmo em seu único envolvimento com a televisão, quando realizou Que país é este?, para a emissora italiana RAI, Hirszman manteve-se no mesmo compasso: neste programa, a partir de uma leitura crítica da história do Brasil, com depoimentos de Sérgio Buarque de Hollanda, Fernando Novais, Alfredo Bosi, Fernando Henrique Cardoso e Maria da Conceição Tavares, articulava-se uma oposição à ideologia do regime militar e a defesa do processo de abertura democrática (5).

A leitura crítica do tempo presente, somada ao compromisso de Leon Hirszman com a prática do marxismo, adquiriu no projeto de $A B C$ da greve, por conta da intensa expectativa em relação ao novo movimento operário, uma dimensão bem mais evidente. Com o anseio de finalmente engajar-se na luta política ao lado do popular, a sua perspectiva, conforme explicou em depoimento concedido no dia 3 de abril de 1979, era fazer deste documentário, primordialmente, um instrumento que servisse como reflexão para a classe trabalhadora brasileira, em especial para aquele setor envolvido com as paralisações no Estado de São Paulo. Ao construir uma síntese dos acontecimentos que ganhariam repercussão nacional nos meses de março a maio de 1979, registrando o confronto ideológico entre os operários, o patronato e os representantes oficiais da ditadura, a pretensão era colaborar a partir de um documento audiovisual que favorecesse a análise sobre o saldo final da greve metalúrgica, seus acertos e equívocos. Ao oferecer-se como articulador da memória social contemporânea, Hirszman propunha, naquele momento, fazer de seu cinema uma peça crítica para provocar discussões e, a partir do exercício dialético, um instrumento intelectual em contribuição ao avançar do movimento trabalhista brasileiro. Vendo-se na tela, o operário poderia avaliar a sua atuação, pensar em novas estratégias para o futuro de sua classe: o documentário, em resposta às inquietações do presente, deveria não apenas registrar a história, mas dela participar ativamente, instigando as definições e redefinições da praxis política organizada pela vanguarda da classe popular. Engajar-se no fazer histórico, eis o sentido último do que Hirszman entendia como participação a partir de $A B C$ da greve:

Mesmo que [o documentário] não "acenda as luzes de todas as casas", como disse Maiakovski, serve para aqueles diretamente ligados à experiência, aos trabalhadores. É importante formar um círculo de trabalhadores que possam se ver, discutir (...). [A classe trabalhadora] é o verdadeiro sujeito do processo [histórico]. Nós somos aqueles que podem organizar esse material e fazer com que sirva à memória dos trabalhadores (...). Não se trabalha mais com virtualidades, com 
metáforas, com relações simbióticas, mas com um dado de caráter definido, concreto (HIRSZMAN, 1991: 8).

O conceito de participação conforme compreendido por Hirszman em 1979 merece, no entanto, uma investigação mais cuidadosa. Estava em jogo naquele momento, em parte pelo esgotamento do modelo implantado pela ditadura, a rearticulação de uma oposição significativa aos militares. Embora permanecessem em vigor os mecanismos de repressão, desde meados dos anos 1970, conforme estudo do sociólogo Éder Sader (6), a classe popular no Estado de São Paulo, em uma chave distinta da leitura marxista, estava se organizando de uma forma nova, em sindicatos, comunidades cristãs de base, clubes de mães e associações de bairro, com a finalidade de exigir do governo ações pontuais para a melhoria da vida. Junto a isso, em outra perspectiva, representantes progressistas da intelectualidade formavam, em 1978, o Comitê Brasileiro pela Anistia (CBA), cuja tarefa mais imediata seria pressionar os militares no sentido de impedir a continuidade das perseguições políticas e o retorno ao país, em segurança, daqueles que haviam sido exilados em decorrência da ditadura. Em 1979, a mobilização metalúrgica no ABC levava a crer, no caso de Leon Hirszman, na possibilidade de unificar estes e outros movimentos, sem desrespeitar as suas singularidades, no sentido de formar uma "frente única" em defesa da redemocratização do Brasil. Para o cineasta, a partir da pluralidade de oposições é o que se daria o avanço democrático,

o aprimoramento [decorre da] organização popular, em todos os níveis, sem chauvinismo, de uma forma pluralista. Precisamos compreender a democracia compreendendo o antagonismo, o processo de diferença, a questão da participação (...) O avanço da luta de classes não impede que se consolide a democracia. Essa questão é complexa, ela pede uma mediação dialética, na qual a práxis política de todas as forças, honestamente comprometidas com a reconquista da democracia no país, deve se empenhar (HIRSZMAN, 1991: 9).

Neste contexto, no qual o popular se tornava uma significativa força de oposição, com autonomia em relação às formas partidárias tradicionais, caberia ao intelectual de formação marxista repensar a própria militância. Não era mais o caso, para Hirszman, de um retorno ao engajamento dos tempos do Centro Popular de Cultura (1961 a 1964), quando havia uma disposição dos artistas próximos ao comunismo em se considerar detentores privilegiados de um saber político que deveria ser, por eles, transmitido ao povo alienado (7). De fato, a eclosão da greve metalúrgica era recebida como a emergência de uma nova disposição política dos trabalhadores, na opinião do cineasta ainda pouco conhecida devido, em parte, à atuação da televisão brasileira, cuja proximidade com o governo favorecia a distorção das notícias acerca do movimento operário. Assim, caso desejasse efetivamente participar do processo de abertura democrática, o intelectual precisaria atualizar seu conhecimento da realidade social em profunda transformação e despir-se da crença anterior de superioridade para concretizar uma parceria efetiva com o popular em luta. Tal era a disposição de Hirszman ao propor $A B C$ da greve como instrumento de reflexão, como a construção, ao lado do trabalhador, de uma síntese histórica, dialética por essência, para pensar a experiência da greve. Para ele, aliás, o documentário também tinha a pretensão de informar o espectador, em geral, sobre os fatos que a ditadura procurava encobrir nos meios de comunicação de massa:

O nosso interesse é outro [diferente do da televisão], recolher uma memória das coisas que desconhecíamos. Estamos saindo da casca do medo. Toda essa couraça que impedia que desabrochasse a consciência do real, do que se passa de fato no país (...) Esse filme ainda é um reflexo de quem vive sob ameaça (...) Aqui em São Paulo (...) não é o intelectual que quer [se tornar o representante do povo], é a massa que exige, no seu processo de organização. A diferença é enorme. De certa forma, já estávamos conscientes de que era necessária uma dramaturgia nova, uma condição nova de ligação entre o intelectual e o povo (HIRSZMAN, 1991: 7; 11). 
Com estas questões em jogo, e na pressa de iniciar as filmagens na região do $\mathrm{ABC}$, Hirszman comprou negativos com parte do financiamento da Embrafilme para Eles não usam black-tie e convidou alguns de seus conhecidos em São Paulo para a realização do documentário. Utilizando seu contato com a Oboré, uma editora de jornais, revistas e livros ligada ao movimento sindical, o cineasta articulou-se com Adrian Cooper, um dos sócios da produtora Tatu Filmes, que acabaria se tornando câmera, fotógrafo e, posteriormente, montador de $A B C$ da greve. Como não dispunha de muitos recursos, Hirszman optou por um sistema alternativo de trabalho: formada também por Cláudio Kahns e Ivan Novais na produção e por Francisco Mou e Uli Bruhn como assistentes de câmera, a reduzida equipe, em troca da participação nos direitos de comercialização do documentário, aceitou emprestar para o filme o equipamento de que dispunha, além de receber metade do salário previsto em tabela sindical (8). Para efetivar o projeto, tratava-se de assumir uma estrutura em cooperativa de certo modo recorrente na história do cinema brasileiro até então.

No caso de Hirszman, no entanto, o sistema de cooperativa encontrava-se em convergência com o sentido de participação por ele esperado em tempos de abertura democrática. Se por um lado poderia ser uma solução para viabilizar a realização independente, autônoma ao mercado e de baixo custo, por outro implicava em uma reformulação do formato tradicional de produção cinematográfica. Conforme defendeu o cineasta, na entrevista para a rádio Jornal do Brasil, embora cada componente de uma equipe se profissionalizasse em uma função específica do fazer fílmico, isto não significava que o processo criativo teria de ser definido centralmente, por vezes de forma autoritária, pela figura do diretor. Sem alterar a divisão de tarefas, pois cada um detém maior conhecimento e experiência de sua própria função, tratavase de propor um modelo alternativo no qual todos os componentes de uma equipe poderiam ter voz ativa no percurso da realização de uma obra. No depoimento aqui citado, possivelmente por influência da análise de Karl Marx, em $O$ capital, sobre as implicações da divisão de trabalho no capitalismo, Hirszman chega, inclusive, a sugerir que este modelo de cinema, por incentivar a integração, permitiria aos envolvidos com o filme evitar uma possível alienação intelectual provocada pelo desconhecimento da totalidade criativa. Eis mais uma dimensão do que o cineasta, naquele momento, compreendia como participação (9).

Não se deve, no entanto, confundir o sentido de cooperativa proposto por Hirszman com uma prática do fazer fílmico que se desenvolveu em parte do cinema realizado em torno do "novo sindicalismo" da região do ABC. Buscando provocar um impasse na tradição do documentarismo social brasileiro, outros cineastas, como foi o caso de Sérgio Segall e Roberto Gervitz (10) propuseram, pelo menos na teoria, uma reflexão sobre a importância não apenas de construir uma trajetória do operário no contexto em que adquiria projeção política, mas principalmente de torná-lo parte ativa no processo de produção cinematográfica. Tratava-se de redefinir a relação convencional entre o realizador e o popular, para eles estabelecida de forma a gerar uma divisão hierárquica na qual o segundo, objeto de interesse, cedia a sua voz ao primeiro que, detentor dos instrumentos de criação, a organizava dentro de uma lógica discursiva por vezes alheia ao próprio povo (11). Dirigida sobretudo ao documentário realizado pelo Cinema Novo em seus primeiros anos, mas sem negar o legado deixado por aquela experiência, a crítica era mobilizada pelo sentimento de que o trabalhador, altamente politizado, deveria ser incorporado à equipe de filmagem, à montagem e mesmo às discussões sobre como o filme seria distribuído e exibido. Afinal, levando-se em conta que o cinema da greve serviria, em essência, como reflexão para o próprio operário, o cineasta deveria construir junto a este, em uma relação criativa nova, a memória da luta e da cultura popular (12).

Embora Hirszman buscasse uma parceria com o trabalhador em greve, segundo o seu entendimento do significado de participação no processo democrático, o cineasta não chegou a compartilhar da proposta brevemente descrita no parágrafo anterior. Pelo contrário. Por desconfiar que este caminho acabaria por submeter o tratamento estético do filme ao debate político, empobrecendo a criação formal em nome da 
ilusão de que as divisões de classe seriam rompidas por um quebra na hierarquia do fazer cinematográfico, Hirszman mostrou-se um opositor das expectativas anunciadas por Segall e Gervitz. Como um dos principais entusiastas, no decorrer dos anos 1970, de um movimento em defesa da sindicalização e da profissionalização do mercado cinematográfico, necessários para assegurar direitos trabalhistas à área, ele se manteve distante de perspectivas que pudessem ser confundidas com o amadorismo ou com o fazer fílmico como experiência diletante. Coerente com este pensamento, a sua proposta era que em tempos de abertura, e a partir de uma pesquisa sistemática da realidade social, o documentarista, como um trabalhador do meio audiovisual, deveria se engajar na construção da memória operária de forma a evitar, ao máximo, a imposição de seu olhar sobre o outro. Sem a ingenuidade de que tal processo levaria à imparcialidade do realizador, à neutralização de sua subjetividade perante os acontecimentos, mas também sem acreditar que a incorporação do popular na equipe de realização fosse algo necessário para representá-lo como classe, Hirszman buscou um ponto de equilíbrio entre o cinema político e a profissionalização do cinema. Ao ser questionado sobre o assunto por Marcos Reis, na já citada entrevista à rádio Jornal do Brasil, ele explicou:

Nós chegamos a um ponto em que a alienação não é superada superando um certo tipo de divisão (...) [Neste processo], a pessoa se aliena inclusive do objeto do discurso, do que ela está pretendendo de um modo mais amplo. Acho que isso é uma deformação, é um preço que muita gente paga (...) Em um país que você achata politicamente, quer esse obscurantismo, essa dificuldade de participação, o sujeito valoriza a política, o próprio artista, de forma desmesurada. E ela hipertrofia e se amplia de tal forma que até esmaga os outros processos, as relações afetivas, as relações democráticas, quer dizer, as relações entre os diferentes propriamente [dito] (...). As relações mesmo estéticas, mesmo cinematográficas (...). O sujeito vira profissional da política e de repente não é mais artista, não consegue mais. A realidade empurra ele para isso, não é por maldade, [mas] não é um dado da formação do sujeito (HIRSZMAN, 1981).

Iniciadas logo após o dia 13 de março de 1979, as filmagens do documentário de Hirszman acompanharam o movimento metalúrgico até o encerramento da greve, no dia 13 de maio, quando as negociações entre os sindicatos metalúrgicos do $\mathrm{ABC}$ e os dirigentes industriais levaram ao encerramento das paralisações em troca de um reajuste salarial abaixo do esperado pelos trabalhadores. Posteriormente predisposto, pelo uso dialético da montagem, a fazer de $A B C$ da greve uma síntese dos conflitos que se desenrolaram durante a greve, Hirszman procurou utilizar técnicas documentais, como a câmera observacional, as entrevistas e o registro das notícias divulgadas na mídia, para compor um quadro das forças políticas em oposição. De um lado, armazenou um valioso material em torno dos esforços conjuntos dos representes da ditadura e da indústria metalúrgica paulista, principalmente as declarações do ministro do Trabalho Murilo Macedo e dos integrantes da diretoria da Fiesp(Federação das Indústrias do Estado de São Paulo) no sentido de esvaziar o movimento operário, de diminuir a sua importância social enquanto manifestação da vontade popular. Em especial, a equipe do documentário se esforçou para filmar as contra-propagandas veiculadas na televisão pelo governo, nas quais salientava-se a greve como ilegal, prejudicial aos negócios e à tranqüilidade da família brasileira.

De outro lado, compondo a maior parte das filmagens, Hirszman acompanhou as mobilizações populares. Como o cineasta belga Joris Ivens, no filme Ellende in de Borinage (1933), cuja tradução literal é Miséria em Borinage, ele não apenas documentou o percurso dos acontecimentos no $\mathrm{ABC}$, como também se deteve nos pormenores da cultura grevista, registrando debates, piquetes nos pontos de ônibus para convencer os operários a não entrarem nas fábricas, a organização do sindicato na formação do Fundo de Greve para distribuir alimentos aos manifestantes, as missas em que a ala progressista da igreja católica ofereceu seu apoio aos trabalhadores, assim como as diversas assembléias realizadas no Estádio de Vila Euclides, nas quais destacou-se a figura de Lula como líder político e carismático do movimento. Sem perder o foco na cronologia dos eventos, Hirszman filmou o confronto entre os populares e a tropa de 
choque da polícia militar, no Paço Municipal de São Bernardo, após a decisão do ministro Murilo Macedo, no dia 23 de março, em utilizar a lei federal para afastar as diretorias dos três sindicatos metalúrgicos do $\mathrm{ABC}$. Registrou a reorganização destas diretorias para continuar liderando as paralisações; a decisão de suspender as atividades grevistas por 45 dias, a partir de 27 de março, na expectativa de avançar as negociações com os patrões; a celebração do primeiro de maio, na qual artistas, estudantes, líderes populares e políticos do MDB ofereceram apoio ao movimento sindical; e finalmente o fim da greve, quando o sindicato considerou o resultado positivo, pois embora o aumento salarial não tivesse sido o esperado, finalmente o operariado abria uma brecha no sentido de mobilizar-se, em massa, no Brasil sob regência do governo militar (13).

Logo após o término das filmagens, contando com apoio da produtora Taba, que assumiu parte da finalização do filme, Hirszman iniciou com Adrian Cooper a montagem de $A B C$ da greve. Mesmo com o compromisso, assumido como urgente, em fazer do documentário uma leitura crítica em torno do movimento operário, o cineasta passaria um ano para transformar as cerca de 25 horas de material existente em algo próximo a um longa- metragem de 90 minutos (14): um período aparentemente longo, se levarmos em conta a pretensão de Hirszman em contribuir com a praxis da classe popular em emergência, mas tempo utilizado para amadurecer o processo de criação do filme, necessário para um artista que sempre exigiu rigor na construção estética de suas obras, jamais aceitando o empobrecimento da forma cinematográfica em privilégio do conteúdo de origem política. $\mathrm{O}$ intenso envolvimento com Eles não usam black-tie entre 1979 e 1981, o projeto mais ambicioso e caro de toda a trajetória de Hirszman, possivelmente explica, em parte, porque ele acabou por não encerrar $A B C$ da greve, apesar da montagem já estar praticamente pronta e a Embrafilme ter firmado, em outubro de 1979, um contrato de distribuição do documentário que permitiria a sua finalização e ampliação de $16 \mathrm{~mm}$ para 35mm (15). Uma explicação possível, a ser investigada com cuidado, talvez provenha do próprio engajamento partidário do cineasta: levando-se em consideração o seu compromisso com o PCB (Partido Comunista Brasileiro), que se colocaria na oposição ao Partido dos Trabalhadores ao apoiar a política do PMDB (Partido do Movimento Democrático Brasileiro) a partir de seu surgimento, em 1980, talvez parecesse contraditório terminar um filme que celebrava a liderança de Lula.

Inacabado nos arquivos da produtora Taba, o projeto de $A B C$ da greve seria retomado apenas em 1989 , dois anos após a morte de Hirszman, quando Adrian Cooper, com apoio da Cinemateca Brasileira, conseguiu finalizar a montagem que havia iniciado com o cineasta dez anos antes. Lançado em 1991, na própria Cinemateca, o documentário, que não foi exibido no circuito comercial de salas de cinema, perdeu definitivamente a intenção original de mobilizar os debates acerca do avanço político da classe popular. A perspectiva de fazer um filme para servir ao tempo presente, às reflexões sobre a experiência operária de 1979, transforma-se, na versão derradeira, em memória dos acontecimentos passados há uma década. Nada restou, em nível extra-fílmico, da noção marxista de História em movimento, conforme pensada por Leon Hirszman, a partir da qual $A B C$ da greve se integraria no processo de construção de um outro Brasil, da abertura democrática. Tal distância em torno do projeto original acabaria por se acentuar ainda mais em decorrência do contexto político vivido pelo país no início dos anos 1990: graças à presidência de Fernando Collor de Melo, o documentário finalizado acabaria realçando, em meio às corrupções de seu governo, a promessa não realizada de um Brasil mais justo, no qual a participação em massa da classe popular na política parecia anunciar ares de novos tempos.

\section{Bibliografia:}

ANTUNES, Ricardo. A rebeldia do trabalho (o confronto operário no ABC Paulista: as greves de 1978/80). Campinas: Ensaio e Editora da Unicamp, 1988. 
BAROT, Emmanuel. "La caméra, arme et symbole de la praxis militante: l'aventure Medvedkine". In: Camera politica: dialectique du réalisme dans le cinéma politique et militant. Paris: Libraire Philosophique J. Vrin, 2009.

BERNARDET, Jean-Claude. Cineastas e imagens do povo. São Paulo: Companhia das Letras, 2003. CALIL, Carlos Augusto; LOURENÇATO, Arnaldo (orgs.). "Leon Hirszman: é bom falar". Catálogo da Mostra Leon de Ouro. Rio de Janeiro: Centro Cultural Banco do Brasil, 1995.

CARDENUTO, Reinaldo. Discursos de intervenção: o cinema de propaganda ideológica para o CPC e o Ipês às vésperas do Golpe de 1964. São Paulo: ECA-USP, 2008 (dissertação de mestrado).

CARDENUTO, Reinaldo. "A voz coletiva do Partido Alto". In: CALIL, Carlos Augusto; CARDENUTO, Reinaldo (orgs.). Leon Hirszman 4. São Paulo: Videofilmes, 2009, pp.52-60.

COOPER, Adrian. "Fazendo a greve junto". In: Cinemateca Brasileira (org.). Leon Hirszman: ABC da greve, documentário inédito. Catálogo de Mostra. Cinemateca Brasileira: São Paulo, 1991, pp.17-23.

FREDERICO, Celso. A vanguarda operária. São Paulo: Símbolo, 1979.

"A GREVE no cinema". In: Escrita ensaio, ano IV, n 7. São Paulo: Editora e Livraria Escrita, abr. de 1980.

HIRSZMAN, Leon. Depoimento concedido à rádio Jornal do Brasil. Rio de Janeiro, set. de 1981.

HIRSZMAN, Leon. "O espião de Deus". In: Cinemateca Brasileira (org.). Leon Hirszman: ABC da greve, documentário inédito. Catálogo de Mostra. Cinemateca Brasileira: São Paulo, 1991, pp.5-16.

NAGIB, Lúcia. "Retrospectiva Leon Hirszman exibe 'ABC da greve'". Folha de S. Paulo, 09/03/1991.

NIGRO, Soraia. "Filmes de Hirszman na Cinemateca". Gazeta de Pinheiros, 10/03/1991.

PÉCAULT, Daniel. Os intelectuais e a política no Brasil. São Paulo: Ática, 1990.

PEREIRA, Edmar. "HIRSZMAN. Na Cinemateca a partir de amanhã, uma retrospectiva da obra do diretor brasileiro, incluindo o documentário ainda inédito, $O A B C$ da greve". Jornal da Tarde, 08/03/1991.

RIDENTI, Marcelo. Em busca do povo brasileiro: artistas da revolução, do CPC a era da TV. São Paulo: Record, 2000.

SADER, Eder. Quando novos personagens entraram em cena. São Paulo: Paz e Terra, 2001.

SALEM, Helena. Leon Hirszman: o navegador de estrelas. Rio de Janeiro: Rocco, 1997.

"SÃO PAULO vê filme de Leon". Jornal do Brasil, 09/03/1991.

SILVA, Maria Carolina Granato da. O cinema na greve e a greve no cinema: memórias dos metalúrgicos do ABC (1979-1991). Niterói: UFF, 2008 (tese de doutorado).

VIANY, Alex. "Leon Hirszman". In: O processo do cinema novo. Rio de Janeiro: Aeroplano, 1999, pp.283-314.

\section{Notas:}

Trabalho apresentado na I Jornada Discente do Programa de Pós-Graduação em Meios e Processos Audiovisuais da Escola de Comunicações e Artes da Universidade de São Paulo (ECA-USP), realizada em novembro de 2010.

(1) Como não tive acesso às informações completas da entrevista concedida por Leon Hirszman à rádio Jornal do Brasil, estou supondo como data aproximada de sua realização o mês de setembro de 1981, já que o cineasta se refere, em diversos momentos, à estréia de Eles não usam black-tie nos cinemas, que aconteceu no Rio de Janeiro e em São Paulo justamente naquele período.

(2) Conforme depoimento de Leon Hirszman a Alex Viany, publicado em VIANY, Alex. "Leon Hirszman". In: O processo do cinema novo. Rio de Janeiro: Aeroplano, 1999, pp.283-314.

(3) Em entrevista concedida para Fernando Morais, Cláudio Kahns, Sérgio Gomes, Adrian Cooper e Uli Bruhn, no dia 3 de abril de 1979, Leon detalha a sua percepção da greve: "O avanço das forças produtivas, no $\mathrm{ABC}$, deu condições para a concentração de uma grande massa, com alto nível de consciência de classe. E isso se expressou nessa batalha que estamos vendo aí, pacífica, organizada e que pode ser de muita valia para todos os trabalhadores do Brasil, para que compreendam a necessidade de 
lutar por seus direitos, de se organizar e vencer a ilegalidade". HIRSMAN, Leon. "O espião de Deus". In: Cinemateca Brasileira (org.). Leon Hirszman: $A B C$ da greve, documentário inédito. Catálogo de Mostra. Cinemateca Brasileira: São Paulo, 1991, pp.5-6.

(4) Sobre Partido alto, ver CARDENUTO, Reinaldo. "A voz coletiva do Partido Alto". In: CALIL, Carlos Augusto; CARDENUTO, Reinaldo (orgs.). Leon Hirszman 4. São Paulo: Videofilmes, 2009, pp.52-60.

(5) Infelizmente, Que país é este? nunca chegou a ser exibido pelo emissora italiana e tampouco Leon Hirszman obteve da RAI uma cópia de seu documentário. Para apresentá-lo no artigo, em linhas gerais, utilizei uma transcrição da banda sonora do filme depositada no Arquivo Edgar Leuenroth, na Unicamp, fundo Leon Hirszman.

(6) SADER, Eder. Quando novos personagens entraram em cena. São Paulo: Paz e Terra, 2001.

(7) Sobre o assunto, consultar RIDENTI, Marcelo. Em busca do povo brasileiro: artistas da revolução, do CPC a era da TV. São Paulo: Record, 2000; PÉCAULT, Daniel. Os intelectuais e a política no Brasil. São Paulo: Ática, 1990; e CARDENUTO, Reinaldo. Discursos de intervenção: o cinema de propaganda ideológica para o CPC e o Ipês às vésperas do Golpe de 1964. São Paulo: ECA-USP, 2008 (dissertação de mestrado).

(8) Estas informações podem ser consultadas em COOPER, Adrian. "Fazendo a greve junto". In: Cinemateca Brasleira (org.). Leon Hirszman: $A B C$ da greve, documentário inédito. Catálogo de Mostra. Cinemateca Brasileira: São Paulo, 1991, pp.17-23. Quando Adrian Cooper cita, neste depoimento publicado em 1991, que a equipe abriu mão de receber o salário integral previsto em tabela,

possivelmente ele estava se referindo aos números do Sindicato dos Artistas e Técnicos em Espetáculos e Diversões (Sated), que no final dos anos 1970 atuava como representante da classe cinematográfica, cujo sindicato estava cassado desde 1969.

(9) Conforme a fala de Adrian Cooper, em entrevista publicada no ano de 1991, parece que realmente Leon Hirszman procurou aplicar esta proposta em ABC da greve: "No decorrer da filmagem, aumentou muito nossa participação, tanto em termos de salário como de aluguel de equipamento, o que acabou dando para a equipe um papel de co-produtora do filme. Acho que isso foi muito bom. Uniu a equipe e nos fez duplamente responsáveis pelo resultado do trabalho. Claro, também está ligado à maneira de Leon trabalhar com a equipe de cinema: ele era excepcionalmente democrático na maneira de pensar o trabalho, estava sempre disposto a ouvir o que as pessoas tinham a dizer, a incorporar as idéias dos outros, a dar um espaço muito grande para as pessoas participarem. Por se tratar de um documentário, eu diria que ele teve mais um papel de coordenador de filmagem do que propriamente de diretor" (COOPER, Adrian. op. cit., p.18).

(10) Conforme depoimento publicado em “A GREVE no cinema”. In: Escrita ensaio, ano IV, nº 7. São Paulo: Editora e Livraria Escrita, abr. de 1980.

(11) Os interessados sobre o assunto, que não é foco central de análise neste artigo, podem consultar BERNARDET, Jean-Claude. Cineastas e imagens do povo. São Paulo: Companhia das Letras, 2003.

(12) Seria deveras interessante o desenvolvimento de uma pesquisa que aproximasse, com o devido cuidado, esta experiência daquela realizada pelo grupo Medvedkine, ao qual pertenceu o cineasta Chris Marker, e que também propôs uma incorporação do popular no processo de criação documental ao retratar o movimento operário francês na passagem dos anos 1960 e 1970 . Sobre o assunto, consultar BAROT, Emmanuel. "La caméra, arme et symbole de la praxis militante: l'aventure Medvedkine". In: Camera politica: dialectique du réalisme dans le cinéma politique et militant. Paris: Libraire

Philosophique J. Vrin, 2009.

(13) Para uma análise detalhada do significado histórico das greves de 1978, 1979 e 1980 na região do ABC paulista, sugiro a leitura de ANTUNES, Ricardo. A rebeldia do trabalho (o confronto operário no ABC Paulista: as greves de 1978/80). Campinas: Ensaio e Editora da Unicamp, 1988. O autor, inclusive, resume na página 61 de seu livro o saldo da greve de 1979: "O aumento material obtido (ainda que bastante aquém do quantum reivindicado); a retomada dos sindicatos operários e a sua restituição às respectivas diretorias; a reafirmação do avanço político do movimento sindical, mostrando os limites do politicismo da ação parlamentar oposicionista; a vitória política que se consolidou ao barrar o projeto 
idealizado pelo Estado ditatorial que visava desestruturar a espinha dorsal do movimento sindical e operário no Brasil; (...) tudo isso permite caracterizar a Greve Geral metalúrgica de março de 1979 como um momento privilegiado da ação operária brasileira, particularmente do pós-1964".

(14) Informações extraídas de COOPER, Adrian. op. cit.

(15) Segundo Carlos Augusto Calil, a Embrafilme firmou o contrato de distribuição em 4 de outubro de 1979. HIRSMAN, Leon. "O espião de Deus". In: Cinemateca Brasileira (org.). Leon Hirszman: ABC da greve, documentário inédito. Catálogo de Mostra. Cinemateca Brasileira: São Paulo, 1991, p.5.

\section{Mini Currículo :}

Mestre em ciências da comunicação pela ECA-USP, foi programador de cinema no Centro Cultural São Paulo e assessor do secretário municipal de cultura Carlos Augusto Calil. Atualmente, além de doutorando no programa de Pós-Graduação em Meios e Processos Audiovisuais da ECA-USP, trabalha na Faap como professor de história do cinema e coordenador do curso de Pós-Graduação em Argumento e Roteiro para Cinema e Televisão. 